\title{
Suicídio, cultura e trabalho em município de colonização alemã no sul do Brasil
}

Stela Nazareth Meneghel ${ }^{(a)}$

Rosylaine Moura ${ }^{(b)}$

Meneghel SN, Moura R. Suicide, culture and work in a German-colonized municipality in the South of Brazil. Interface (Botucatu). 2018; 22(67):1135-46.

Suicide is a serious public health issue with increasing rates. The state of Rio Grande do Sul, Brazil, has a history of high mortality rates, mainly in regions colonized by German populations. The present investigation is a social case study, whose information was obtained through narratives of 14 informers from the health, agriculture, justice, public safety, social communication and education fields. The decisive factors for suicide reported by the informers were the German culture, protestant ethics and suffering at work, which affects family farmers who grow tobacco. The reflections of the interviewees point to suicide as a resource used in the culture of people who descend from German populations to cope with difficulties, which persists as a consequence of the introduction of capitalism in the countryside and the subordination of producers to the tobacco industry.

Keywords: Suicide. Work. Protestant ethics. German culture.
O suicídio é um problema de saúde pública de magnitude elevada e ascendente. No Brasil, o Rio Grande do Sul tem apresentado, historicamente, altas taxas de mortalidade, sobretudo em regiões colonizadas por alemães. Este é um estudo de caso social, cujas informações foram produzidas com base em narrativas de 14 informantes-chave, pertencentes aos campos da saúde, agricultura, justiça, segurança pública, comunicação social e educação. Os determinantes atribuídos pelos informantes ao suicídio incluíram: a cultura germânica, a ética protestante e o sofrimento no trabalho que afeta agricultores que trabalham com o fumo em regime de pequena propriedade familiar. As reflexões dos entrevistados apontam para o suicídio como um recurso usado na cultura desses descendentes de alemães para enfrentar as dificuldades, cuja frequência se manteve com a introdução do capitalismo no campo e com a subordinação dos agricultores à indústria fumageira.

Palavras-chave: Suicídio. Trabalho. Ética protestante. Cultura alemã.

\author{
Rosylaine Moura
}




\section{Introdução}

O suicídio é considerado o ato humano de infligir a si próprio o fim da vida ${ }^{1}$, resultado de um ato deliberado e executado por uma pessoa com pleno conhecimento do desfecho fatal ${ }^{2}$.

No Brasil, o Rio Grande do Sul apresenta, historicamente, os maiores coeficientes de mortalidade ${ }^{3-5}$, ocorrendo, sobretudo, com agricultores e em municípios de pequeno ou médio porte. O município de Santa Cruz do Sul apresentou a sétima posição no país, durante o triênio 2005-2007, mantendo tendência ascendente e configurando um grave problema de saúde pública ${ }^{5,6}$.

Entre os possíveis determinantes do suicídio, uma das hipóteses refere-se à influência da ética do trabalho presente na cultura germânica, já que municípios de colonização alemã apresentam elevada prevalência de suicídios.

Durkheim 7 , estudando o suicídio em países europeus, encontrou altas taxas na Saxônia, uma região que fazia parte do Império alemão. Um século mais tarde, pesquisadores exploraram a relação que parecia ocorrer no Brasil, entre altas taxas de suicídio e municípios colonizados por alemães ${ }^{8-11}$. Os imigrantes alemães que vieram para o Brasil eram, em sua maioria, luteranos, embora houvesse subgrupos de católicos.

Para Durkheim", as normas morais veiculadas por meio da religião, leis e costumes são responsáveis pela manutenção da coesão na sociedade; e, quando há quebra dessas regras, ocorre desestabilização, gerando uma situação denominada anomia, em que os laços de solidariedade ficam enfraquecidos, podendo haver aumento no número de suicídios.

No Rio Grande do Sul, vários pesquisadores investigaram a presença do comportamento suicida em agricultores que trabalhavam com o fumo, a partir da pressuposição de relação entre uso de agrotóxicos, depressão e suicídio ${ }^{12,13}$. Porém, descendentes de alemães em municípios onde não há produção de fumo apresentam altas frequências de comportamento suicida ${ }^{8,9}$. Para Heck ${ }^{9}$, o mais importante não é saber quantos descendentes de alemães se suicidam, mas entender como esses remanescentes da colonização elaboram suas razões para resistirem na terra em que vivem frente às dificuldades de sobrevivência com a entrada do capitalismo no campo, diante da qual houve expansão do processo de assalariamento rural, empobrecimento e perda de autonomia ${ }^{14}$.

A vertente teórico-metodológica denominada psicodinâmica do trabalho ${ }^{15}$ tem estudado o suicídio no ambiente laboral, embora o sofrimento gerado pelo trabalho e seus efeitos sobre a saúde mental e a vontade de morrer dos trabalhadores ainda seja pouco estudado. As situações que podem aumentar a incidência de suicídios no trabalho incluem: as recessões econômicas e os ajustes estruturais na economia que levam ao aumento de demissões, desemprego, falência e trabalho precário em contextos de superexploração ${ }^{16,17}$.

Os novos arranjos do capitalismo, em sua etapa global, utilizam: a desregulamentação, a flexibilização, a terceirização, a precarização do trabalho em benefício do capital e em detrimento do trabalhador ${ }^{18}$. A micropolítica da sujeição é instrumento de controle para desestruturar, emocionalmente, os trabalhadores, além do estímulo à competitividade, à indiferença com o outro e à atribuição de culpa, pelo fracasso, ao indivíduo, gerando insegurança quanto à permanência no emprego ou à perda da terra. Em relação a esses contextos, emergem as patologias do medo, caracterizadas por angústia, mal-estar e ansiedade frente ao futuro, associadas ao aumento de suicídios relacionados ao trabalho ${ }^{19,20}$.

A inserção da lógica capitalista na área rural acarretou uma das mudanças sociais mais profundas da segunda metade do século XX: a morte do campesinato ${ }^{21}$. Para Ianni ${ }^{22}$, o mundo rural encontra-se ocupado por empresas, corporações e conglomerados industriais, que transformaram os processos de produção para ampliar o lucro e a mais-valia. Essa mudança ocorreu e está acontecendo no meio rural brasileiro - o que Werlang ${ }^{23}$ chama de desruralização, processo em que os vínculos do agricultor com a terra são desfeitos e seu trabalho é expropriado em um cenário de exploração que atinge esse setor em âmbito mundial ${ }^{24}$.

O sofrimento gerado pelo trabalho pode levar ao suicídio, assim como a falta de trabalho, o desemprego ${ }^{25}$. A perda do emprego é considerada incompetência do trabalhador e a culpa pela demissão é transferida ao próprio empregado. Assim, quando o suicídio ocorre em chão de fábrica ou 
local de trabalho, como no caso de um galpão de fumo para o trabalhador rural, o ato significa uma denúncia das condições laborais ${ }^{15,26,27}$.

Em algumas regiões do Rio Grande do Sul, colonizadas por imigrantes alemães, como o município de Santa Cruz do Sul, há uma combinação de condicionantes socioculturais, econômicos e psicológicos, que aumentam o risco de suicídio. Dentre eles, pode-se pensar na ética do trabalho herdada pelos imigrantes alemães que vivem na região; na subordinação à agroindústria fumageira transnacional; na sobrecarga exigida pelo trabalho familiar nas pequenas propriedades produtoras de fumo, e no temor da perda da terra frente à entrada do capitalismo no campo. Frente a esse quadro, pode-se acrescentar a permanência transgeracional do comportamento suicida adotada para a resolução de problemas ${ }^{28-31}$.

O objetivo deste estudo é, portanto, a reflexão sobre a cultura alemã e a ética do trabalho como determinantes do suicídio, em um município colonizado por alemães e cuja atividade predominante está ligada à monocultura do fumo.

\section{Metodologia}

Este é um estudo de caso social, em que se buscou conhecer, em profundidade, uma situação única, para aprofundar o que há nela de singular ${ }^{32,33}$, objetivando ampliar a compreensão do fenômeno em regiões similares. O caso selecionado foi Santa Cruz do Sul, um município de imigração alemã, com população de 126.775 habitantes $^{34}$ e cuja principal produção é o fumo. Segundo o Datasus, o município apresenta alta mortalidade por suicídio e, em 2013, a taxa de mortalidade foi de 22,5 óbitos por 100.000 habitantes, em comparação com a média nacional de cinco óbitos para cada 100.000 habitantes.

A produção de informações ocorreu por meio de entrevistas temáticas com 14 informantes-chave, que atuam nos setores: saúde (sete profissionais), agricultura (um funcionário da EMATER e outro do sindicato dos trabalhadores rurais), justiça (um promotor), segurança pública (um servidor) e comunicação social (um jornalista). Além destes, foram entrevistados dois pesquisadores, professores da Universidade local. Quatro informantes se consideram de etnia alemã e cinco são naturais do município.

A seleção dos informantes foi ocorrendo ao longo da pesquisa; os profissionais de saúde foram os primeiros entrevistados, e os demais incluídos por indicação. As narrativas foram produzidas em entrevistas semiestruturadas com duração que variou de 30 a 90 minutos.

As narrativas foram consideradas um constructo coletivo, pois, em sua elaboração, o narrador utiliza princípios e lógicas culturais, expressando crenças, opiniões e pontos de vista referentes à sociedade em que vive ${ }^{35}$. Assim, o sujeito, além de falar por si, fala do grupo em que está inserido, revelando ideias que circulam na localidade. Esses depoimentos, embora marcados pelos pontos de vista dos informantes, trazem elementos que auxiliam a compreender o fenômeno na sua dimensão local.

Para a análise dos dados qualitativos, realizou-se uma leitura exaustiva das gravações das falas dos informantes-chave, e identificaram-se as atribuições causais mais significativas. Os informantes, ao falarem sobre o suicídio em Santa Cruz do Sul, remontaram ao passado, contaram e recontaram histórias da cidade e da colonização, teceram considerações sobre a cultura germânica, a ética do trabalho protestante e o trabalho com o fumo.

Uma questão importante consistia em conhecer o ponto de vista desses informantes-chave sobre as causas dos suicídios. As respostas foram agrupadas em categorias: fatores individuais (psicológicos, relacionais, familiares e morbidades), fatores ligados ao trabalho (pequena propriedade rural, trabalho com o fumo, endividamento e perda da terra), fatores ligados à cultura (cultura alemã, ética protestante); e um informante podia indicar mais de uma causa e atribuir graus de importância a elas. Neste estudo apresentam-se fatores ligados ao trabalho e à cultura alemã.

As narrativas foram agrupadas em, apenas, um conjunto, compondo um texto único, elaborado com base em muitas conversas, mas apresentado como se fosse uma única voz, como se tratasse da fala de, apenas, um narrador. Esse cuidado foi realizado para não identificar os informantes-chave e 
para potencializar as informações produzidas, na medida em que foram sendo acrescentadas a cada tema as várias perspectivas manifestas.

A pesquisa foi aprovada pelo Comitê de Ética em Pesquisa (CEP) da Universidade Federal do Rio Grande do Sul, sob o n 25.922.

\section{Cultura, trabalho e suicídio em um município de "alemães" do Rio Grande do Sul}

\section{A visão de mundo dos colonos alemães}

Para apresentar o município em estudo, remonta-se ao processo migratório implementado nos estados do sul do Brasil com a vinda dos primeiros colonos alemães, a partir de 1824. Os alemães se estabeleceram em mais de uma centena de núcleos, onde houve a formação de sociedades camponesas com a economia baseada na policultura realizada em pequenas propriedades familiares ${ }^{36}$.

Nas regiões de imigração alemã, a valoração do trabalho e da poupança como elementos-chave para atingir o êxito econômico afetaram não apenas os descendentes de imigrantes, mas todos os grupos étnicos que ali vivem ${ }^{11}$. A propriedade de uma colônia e o estilo de vida comunitário constituíram a identidade social do colono, que persiste até a atualidade ${ }^{36,37}$. As narrativas ouvidas reforçaram essa ideia:

Antigamente, no meio rural se falava muito em 'nervenkrankheit' que em alemão quer dizer doença dos nervos. Isso parece reforçar a questão cultural, talvez os de origem germânica sejam mais exigentes consigo mesmos, possivelmente os luteranos se cobrem mais. Algo na cultura dos alemães faz com que o índice de suicídio seja mais elevado, comparando com cidades de origem portuguesa.

Essas constatações parecem se referir aos princípios da ética protestante, que Max Weber ${ }^{38}$, ao analisar o surgimento do capitalismo, encontrou em relação ao protestantismo, religião que, contraditoriamente, propunha a simplicidade e a frugalidade, mas utilizava essas características para aumentar a exigência frente ao trabalho e acumular riquezas. Cada um é responsável pelo êxito e pelos recursos financeiros que consegue acumular durante a vida, o que dificulta a aceitação dos reveses econômicos, já que a responsabilidade é individual frente à fortuna ou à ruína. A perspectiva weberiana $^{38}$ da ética protestante em sua relação com o capitalismo acentua a ideia do trabalho como dever. Consequentemente, há uma relação entre trabalho e acumulação, que propicia a geração de lucro, condizente com o espírito do capitalismo.

Os princípios morais da ética protestante valorizam a meritocracia e a livre iniciativa e consideram o lucro como sinal de eleição - visto que essa recompensa divina já estaria predeterminada, de acordo com a doutrina da predestinação. Os alemães que vieram para o Brasil trouxeram esses princípios em sua bagagem: o valor do trabalho, a conquista metódica da riqueza por meio do labor contínuo, da economia e poupança, a busca de bens materiais e o acúmulo do capital para agradar a Deus ${ }^{38}$. Dessa maneira, pode-se entender o sentimento trágico que assola esses homens e mulheres frente ao fracasso econômico, visto como devido à sua incapacidade de administrar os bens, e não é de admirar que se suicidem, como aponta o narrador:

o protestante sempre diz que não é pecado ser rico, é bom ser rico, é bom o capitalismo. Ele não avalia a questão de explorar o próximo, do sucesso a qualquer preço, de oprimir o outro para ganhar mais. Mas, com a crise do capitalismo, a pessoa não vê mais a luz no fim do túnel, perde a esperança, não vê mais saída e se sente um ninguém, acha que morrer é melhor. Até que ponto essa compulsão que parece genética não é uma predisposição veiculada pela cultura?

Para Durkheim ${ }^{7}$, não se deveriam buscar as causas do suicídio em características individuais, já que o suicídio é um fato social e o que vai explicar o comportamento suicida é o ethos ou a visão de mundo de um povo ou grupo, pensado como o sentido que esse grupo dá a si mesmo, à vida e à morte. 
Então, é preciso entender que elementos velhos e novos misturados influenciaram a visão de mundo desses alemães no Brasil; e como essa visão pode ajudar ou não nos embates frente aos novos processos de exploração do trabalho rural, com que se defrontam na atualidade ${ }^{9}$. Uma cultura de honra em que questões referentes à vida familiar, aos papéis de gênero, à identidade de pequenos proprietários rurais ou colonos, às decisões sobre o uso da terra são tensionadas pelas novas exigências do capitalismo.

A masculinidade em sociedades rurais tradicionais está vinculada: ao estereótipo do homem provedor, do chefe de família que precisa sustentar a casa, demonstra força e coragem, decide o que plantar e quando vender, faz empréstimos e hipotecas ou veta qualquer empreendimento que lhe pareça arriscado ${ }^{39,40}$. Porém, quando esse homem perde a propriedade da terra e precisa migrar para a cidade, se não consegue trabalho, ele passa a ser considerado um incapaz e pode pensar em se matar, como conta o narrador, agora do setor saúde:

Eu já tive pacientes com 20 anos de serviço que perderam o emprego e tentaram o suicídio. Para as mulheres não é problema, porque quando elas perdem o emprego de safristas, passam a trabalhar como faxineiras. Mas para o homem é diferente, ele é o chefe da família, então isso pesa porque quando ele vai para casa desempregado, ele não consegue olhar os filhos, a mulher. Passa o tempo e se ele não acha emprego, se sente diminuído e culpado porque a sociedade não admite que o homem fique sem trabalhar.

O narrador considera que "a perda do trabalho para as mulheres não é importante porque elas passam a trabalhar como faxineiras", porém, na agricultura, a divisão sexual do trabalho significa que, além do cuidado da casa, dos filhos, da horta, dos animais domésticos, elas precisam auxiliar em todas as etapas do cultivo do fumo; e a sobrecarga pela dupla função de agricultoras e donas de casa produz adoecimento, mal-estar e até suicídio, mesmo em menores proporções que os homens ${ }^{31,40}$.

Os descendentes de colonos alemães que vieram para o Brasil seguem mantendo tradições, costumes e modos de pensar vigentes desde a época da imigração, entre eles uma visão de mundo tradicional, compatível com sociedades de honra, na qual a ética do trabalho daqueles primeiros luteranos, ainda, parece estar presente.

\section{O trabalho nas pequenas propriedades rurais}

O cenário rural de Santa Cruz do Sul sofreu mudanças estruturais nas últimas décadas, e, na atualidade, presencia a luta pela sobrevivência desses descendentes de colonos alemães. Desde o momento da chegada ao Brasil, eles começaram a trabalhar com o fumo, um produto para a exportação, que significava um excedente financeiro e uma moeda de troca a ser aplicada em produtos adquiridos no mercado externo ${ }^{41,42}$.

Nos anos 1970, frente à crise mundial do capitalismo, as indústrias multinacionais começaram a transferir as fábricas para países do Terceiro Mundo. Instalou-se, então, em Santa Cruz do Sul, o complexo agroindustrial-fumageiro com o intuito de processar o fumo produzido na região, e a cidade torna-se a principal produtora brasileira de fumo. Na área rural, as multinacionais começaram a impor um modelo tecnológico rígido, utilizando sementes selecionadas, agrotóxicos, fertilizantes e estufas, para aumentar a produtividade ${ }^{43}$.

No entanto, a modernização do processo de cultivo não significou a mecanização da lavoura e mudanças nas relações de produção, que seguiram o modo não capitalista, por meio do trabalho familiar. A produção aumentou pelo aprofundamento da exploração da mão de obra familiar subordinada aos interesses e receituário técnico das empresas multinacionais e aos ditames do mercado. Desse modo, as agroindústrias fumageiras, por meio do monopólio do mercado do fumo e da extração do excedente do trabalho familiar, mantêm os agricultores subordinados ao capital internacional ${ }^{44,45}$.

A agricultura familiar realizada nas pequenas propriedades pressupõe interdependência entre 0 grupo, que, muitas vezes, significa cessão da maior parte do tempo às atividades laborais. Inclui: 
trabalho infantil, de mulheres e de idosos, ausência de diversões e sociabilidades. As narrativas mostraram a intensificação desse quadro, gerando depressão, apatia, falta de perspectivas e exacerbando os conflitos entre gerações e as condutas autodestrutivas: "O jovem do meio rural quer ir para o meio urbano, não há muitas perspectivas no meio rural. Mas por outro lado, tem muito conformismo com a situação, com o descrédito de que algo vai ser diferente, de que a vida vai melhorar. Esse sofrimento passa de geração a geração".

Os agricultores são reféns das fumageiras que compram a matéria-prima e thes impõem condições cada vez mais duras. Em todo o processo, o controle da produção é rígido, o risco de perda das safras é uma ameaça sempre presente, e, a cada ano, um contingente de pequenos agricultores é descartado por não ter alcançado as metas. Para o informante, um pesquisador local do campo dos estudos rurais:

[...] a vida no campo deixou de ser aquela em que se produzia e se tinha tempo e autonomia. Cada vez mais, há interferências na vida do homem do campo e hoje o meio rural está pautado pelo urbano. Os agricultores não têm mais uma renda considerável, o pagamento é anual, se eles perdem a safra ficam sem nada. Têm famílias que se dedicam totalmente para uma cultura que não produz comida [o fumo] e se há perda, não resta nada. Eles trabalham o ano inteiro para vender a safra do fumo e garantir o sustento no ano seguinte. Se perdem, como nos anos em que há uma catástrofe, uma estiagem ou temporais, neste ano acontecem três, quatro ou mais suicídios...

O modelo econômico causa efeitos nas subjetividades, produzindo sentimentos de impotência e desesperança. Não é apenas a relação entre pobreza e suicídio ${ }^{46,47}$, mas a falta de controle sobre a vida e o futuro que torna os sujeitos impotentes ${ }^{48}$ e propensos a buscarem a morte. Muitos são obrigados a vender parte e até toda a propriedade agrícola, para pagarem dívidas ${ }^{49}$. "Eles se endividam e como não gostam de ter o nome sujo na praça, isso é uma das possíveis causas do suicídio".

O aumento da produção de fumo no mercado internacional foi acompanhado de mudanças no beneficiamento industrial do produto e no emprego de tecnologias sofisticadas para aumentar os níveis de produtividade e diminuir o tempo da safra, concentrando-a em um período de quatro a seis meses. Como o fumo é um produto perecível, na safra há necessidade de grande número de trabalhadores contratados temporariamente. No restante do ano, essa população de empregados temporários vive de atividades informais e, embora muitos venham do interior, a maioria reside na periferia urbana, onde há elevada frequência de suicídios ${ }^{50}$. Há um exército de reserva de safristas, que vivenciam o desemprego como condição permanente ${ }^{43}$.

Os trabalhadores rurais sofrem a mesma instabilidade, pois se dedicam quase que exclusivamente à monocultura do tabaco, que lhes propicia uma única safra anual e constitui o rendimento total da família. O valor a ser pago pela indústria fumageira ao produto somente é conhecido após longa rodada de negociações entre representantes dos fumicultores e da indústria; e o valor estabelecido para a folha de fumo depende das condições climáticas, das variáveis econômicas e fiscais do país e dos interesses da indústria de capital estrangeiro. A saturação e o preço do fumo no mercado internacional fazem com que a empresa classifique o produto como de qualidade inferior e, como consequência, ocorre a baixa do preço, reduzindo a lucratividade do agricultor ${ }^{51}$. $\mathrm{O}$ informante que estuda o rural, aponta:

Esse vínculo da indústria com o produtor deixa o agricultor preso à fumageira. Quando o agricultor fala do trabalho, ele diz: 'vou entregar o fumo', ele entrega para alguém o produto do seu trabalho. Ele sente que não é dele, que não têm autonomia para decidir nada. É um instrutor que decide como deve ser realizado o processo de trabalho. Na produção do fumo, o agricultor só sabe que vai vender o produto, mas nunca sabe se vai obter o preço que espera. Esse sistema deixa as pessoas pressionadas, acrescido da questão cultural que torna difícil lidar com as adversidades. 


\section{Os efeitos do trabalho: "um trabalho que mata"}

Para o agricultor de Santa Cruz do Sul, o trabalho é uma atividade que maltrata, não respeita os limites do corpo, exaure ${ }^{52}$, podendo, ainda, causar adoecimento e morte: "A frustração na safra traz uma tensão muito grande para a família. Quando a safra do fumo tem baixa produtividade, aumenta o endividamento das famílias e muitos homens se suicidam".

Houve relatos de suicídios altruístas, aqueles que, segundo Durkheim ${ }^{7}$, teriam a pretensão de trazer algum benefício aos sobreviventes. O objetivo desses agricultores ou safristas é deixar uma pensão ou herança para os familiares, já que são realizados em situações de débito com a fumageira ou banco, havendo risco de perda da terra hipotecada. Mas a única herança que a família recebe é a própria dívida:

No interior, se o fumo não deu certo é como se tivesse terminado o mundo. Eles acreditam que se morrerem vão deixar a família bem. Porém, a dívida fica e, além da dívida, a culpa e o remorso para os sobreviventes. [Os safristas desempregados ou doentes] encontram muita dificuldade para conseguir benefício, então sem dinheiro e sem recursos para se tratarem, ficam deprimidos, nervosos, não dormem, precisariam tomar um antidepressivo, e não têm dinheiro porque vai faltar para comida, vai faltar para os filhos. Qual a solução que eles encontram? Se matar. Acreditam que assim a família fica amparada, se ele morrer a mulher receberá a aposentadoria por viuvez.

O suicídio relacionado ao trabalho está blindado por um "pacto de silêncio"15, ou uma espécie de tabu para a população local e as famílias afetadas. Isso vai produzindo indiferença frente ao sofrimento e aos sintomas psicopatológicos. Mesmo quando há um sintoma ou uma doença, se é uma queixa de ordem psíquica, ela pode ser subestimada e desqualificada, considerada um subterfúgio para burlar o trabalho. Essa situação ficou patente nos depoimentos de informantes que atuavam no sindicato e na assistência ao trabalhador rural:

A depressão é vista como frescura, como vagabundagem, o alcoolismo é visto como semvergonhice, a família diz que não vai gastar dinheiro com aquele vagabundo. A sociedade não admite o homem sem trabalhar, muitos deles estão desempregados, estão doentes, tentam o INSS, tentam se encostar, mas não conseguem porque há um preconceito na sociedade em relação ao sofrimento mental.

Quando ocorre um suicídio no local de trabalho, significa que as estratégias de defesa que o trabalhador possa ter usado - como a negação do sofrimento, a medicalização e, mesmo, a ajuda de companheiros e familiares - não surtiram efeito. Um suicídio ligado ao trabalho indica um estado de degradação no tecido humano e social onde esse evento se produz e representa uma denúncia de uma situação coletiva, embora seja mais fácil atribuí-lo ao indivíduo que morreu ${ }^{53}$.

$\mathrm{Na}$ pesquisa realizada sobre suicídios em idosos, a maioria das autópsias psicossociais foi realizada nas propriedades dos familiares ${ }^{54}$. No Rio Grande do Sul, muitos haviam se enforcado nos galpões de fumo, e os sobreviventes fizeram questão de mostrar as traves ou "tesouras" que serviram para amarrar a corda e onde acharam o corpo ${ }^{11,55}$. Esses suicídios não foram percebidos como ligados ao trabalho nem pelos familiares, nem pela população local. Mas, se o suicídio no local de trabalho funciona como uma mensagem ou denúncia das condições de vida daquele grupo do qual o suicida é o porta-voz, o fato de os familiares levarem os pesquisadores para os galpões de fumo ou local de trabalho representa uma constatação - mesmo não verbalizada - de que o trabalho teve um papel crucial na realização do ato.

A forma como os indivíduos vivem, sofrem e sublimam os sentimentos na atividade laboral está intimamente associada ao valor moral atribuído ao trabalho e sua importância na configuração do ideal de eu, ou os valores em relação aos quais os indivíduos julgam o sucesso ou o fracasso de suas vidas $^{39}$. Em um cenário de cultura germânica, onde o trabalho é parte importante da identidade desses 
sujeitos, a falência, a perda econômica, o insucesso material representam uma marca tão terrível, que só a morte pode(ria) apagar. A percepção do(s) narrador(es) ouvidos nesta pesquisa reafirmou essa asserção, mostrando que a perda da terra, o desemprego e o desamparo econômico parecem ser o gatilho do desejo de morte, para os remanescentes de uma cultura em que honrar os compromissos e atingir sucesso econômico eram (e continuam sendo) valores fundamentais.

Embora não se tenha a pretensão de desvendar as causas complexas desse fenômeno multicausal, em Santa Cruz do Sul, as narrativas dos informantes indicam que a presença de dois elementos: a visão de mundo perpassada pela ética do trabalho trazida pelos colonos germânicos e mantida até o contemporâneo, e os embates econômicos com que os pequenos proprietários rurais se defrontam frente à entrada do capitalismo no campo, podem ser responsáveis pela mortalidade por suicídio nesses locais:

O que chama a atenção em relação ao suicídio é a questão financeira, é o baque financeiro que o cidadão tem na cidade e no campo. Quando a lavoura vai mal e há muitas dívidas, ele se desespera e quer morrer. Na cidade é a perda de emprego na faixa etária dos cinquenta anos. Ele não vai mais conseguir emprego, então o indivíduo castrado na sua autoestima sente-se desvalido, revoltado, injustiçado e é comum tentar o suicídio...

A reestruturação produtiva na agricultura, que ocorreu no Brasil com a globalização, incidiu, pesadamente, sobre a pequena propriedade rural, acarretando impactos que culminaram com: maior concentração da propriedade da terra, fragmentação do espaço agrícola e incremento da urbanização, implantando-se um modelo que promoveu, como nenhum outro, pobreza, desigualdade, sofrimento e morte ${ }^{56}$

\section{Considerações finais}

No mundo contemporâneo, as perdas financeiras e o sofrimento ligado ao trabalho constituem alguns dos determinantes do suicídio. Em culturas tradicionais, como a de agricultores de origem germânica, a ética do trabalho pressupõe que, quando eles não conseguem cumprir os compromissos firmados, podem atentar contra a própria vida ${ }^{57,58}$.

Esta pesquisa propôs-se a estudar um caso único, o município de Santa Cruz do Sul, para aprofundar a reflexão sobre esse tema complexo, multifacetado e sujeito a controvérsias. Uma contribuição alcançada foi a sistematização de uma narrativa com base nas percepções dos entrevistados, trazendo os significados atribuídos ao suicídio por atores que, embora não vivenciem diretamente o problema, estudam e atendem pessoas atingidas, estando em posição de proximidade com os trabalhadores rurais locais.

Realizou-se um esforço analítico para deixar emergir, dentre as múltiplas narrativas e atribuições causais, aquelas que mostraram maior consistência. O trabalho desses colonos "alemães" nas pequenas propriedades rurais, hoje submetidas a um processo de desruralização, que inclui a perda de autonomia e a dependência da indústria fumageira, foi considerado, pelos narradores, como um determinante que gera sofrimento e pode contribuir para a busca da morte. "Em Santa Cruz, o trabalho - e o não trabalho - matam", foi a mensagem que julgamos decifrar.

Como a maioria dos informantes-chave narrou, os cenários econômicos e culturais influenciam a ocorrência do suicídio no município e na região. Enfatizaram o papel da ética do trabalho e da cultura trazidas da Alemanha no século dezenove, e quanto ela segue presente na vida dos fumicultores, expressa na exigência desmesurada de desempenho e no medo onipresente da falência e da perda das terras. Mesmo assim, as categorias analíticas do estudo, cultura alemã e ética do trabalho, não foram esgotadas nessa discussão e precisam ser ampliadas e aprofundadas.

Uma das limitações deste estudo é que, ao enveredar no campo da história da imigração alemã no Rio Grande do Sul e dos estudos do rural, não se investigaram outros fatores causais. Ao organizar esta narrativa, fatores causais podem ter ficado subsumidos em questões mais amplas. Mesmo assim, 
acreditamos que a recuperação da memória desses atores que estudam, trabalham ou se identificam com os "alemães brasileiros" de Santa Cruz do Sul pode trazer alguma contribuição, mesmo que modesta, para o estudo do suicídio e, em decorrência, para a sua prevenção.

\section{Colaboradores}

As autoras participaram de todas as etapas da elaboração do artigo.

\section{Referências}

1. Shneidman E. Definition of suicide. New York: John Wiley \& Sons; 1985.

2. World Health Organization. The world health report 2001: mental health, new understanding, and new hope. Geneve: WHO; 2001.

3. Lovisi GM, Santos AS, Lagay L, Abelha L, Valencia E. Análise epidemiológica do suicídio no Brasil entre 1980 e 2006. Rev Bras Psiquiatr. 2009; 31 Supl 2: 86-94.

4. Marín-León L, Oliveira HB, Botega NJ. Suicide in Brazil, 2004-2010: the importance of small countries. Rev Panam Salud Publica. 2012; 32(5):351-9.

5. Nogueira RC. Repercussões de projeto de implantação de rede intersetorial de prevenção do suicídio em municípios do Rio Grande do Sul [dissertação]. Rio de Janeiro: Universidade Estácio de Sá; 2013.

6. Pinto LW, Assis SG, Pires TO. Mortalidade por suicídio em pessoas com 60 anos ou mais nos municípios brasileiros no período de 1996 a 2007. Cienc Saude Colet. 2012; 7(8):1963-72.

7. Durkheim E. O suicídio: um estudo sociológico. Rio de Janeiro: Zahar Editores; 1982.

8. Heck MR. Suicídio: um grito sem eco - contexto social de Santo Cristo. Pelotas: Ed. UFPEL; 1994.

9. Heck MR. Contexto sociocultural dos suicídios de colonos alemães: um estudo interdisciplinar para a enfermagem [tese]. Florianópolis: Universidade Federal de Santa Catarina; 2000.

10. Capucho MC, Jardim AP. Os pomeranos e a violência: a percepção de descendentes de imigrantes pomeranos sobre o alto índice de suicídio e homicídio na Comunidade de Santa Maria de Jetibá. Gerais Rev Interinstitucional Psicol. 2013; 6(1):36-53.

11. Meneghel SN. Algumas reflexões acerca do suicídio e do comportamento suicida. In: Minayo MC, Figueiredo AEB, Silva RM, organizadoras. Comportamento suicida em idosos. Fortaleza: Edições UFC; 2016. p. 93-118. 
12. Falk JW, Carvalho LA, Silva LR, Pinheiro SRS. Suicídio e doença mental em Venâncio Aires - RS: consequência do uso de agrotóxicos organofosforados? [projeto de pesquisa]. Porto Alegre: Universidade Federal do Rio Grande do Sul; 1996.

13. Trapé $A Z$, Botega JN. Inquérito de morbidade auto-referida e exposição a agrotóxicos. In: Etges $V E$, Ferreira MAF, organizadores. A produção de tabaco: impacto no ecossistema e na saúde humana na região de Santa Cruz do Sul/RS. Santa Cruz do Sul: EDUNISC; 2006. p. 116-41.

14. Talaska A. O espaço agrário brasileiro na perspectiva conceitual: dos aspectos legais às implicações territoriais [tese]. Santa Cruz do Sul: Universidade de Santa Cruz do Sul; 2015.

15. Dejours C, Bègue F. Suicídio e trabalho: o que fazer? Brasília: Paralelo 15; 2010.

16. World Health Organization. Preventing suicide: a global imperative. Geneve: WHO; 2014.

17. Cleary A. Suicidal action, emotional expression and the performance of masculinities. Soc Sci Med. 2012; 74(4):498-505.

18. Antunes R. Crise capitalista contemporânea e as transformações do mundo do trabalho. Universidade de Brasília: CEAD; 1999.

19. Barreto MMS. Uma jornada de humilhações [dissertação]. São Paulo: Pontifícia Universidade Católica; 2000.

20. Venco S, Barreto M. O sentido social do suicídio no trabalho. Rev Espaç Acad. 2010; 9(108):1-8

21. Hobsbawm EJ. O novo século: entrevista a António Políto. São Paulo: Companhia da Letras; 2000.

22. Ianni O. Globalização: novo paradigma das ciências sociais. Estud Av. 1994; 8(21):147-63.

23. Werlang R. Pra que mexer nisso? Suicídio e sofrimento social no meio rural [tese]. Porto Alegre: UFRGS; 2013.

24. Etges VE. Sujeição e resistência: os camponeses gaúchos e a indústria do fumo. Santa Cruz do Sul: Livraria e Editora da FISC; 1991.

25. Minayo MC, Meneghel SN, Cavalcante FG. Suicídio de homens idosos no Brasil. Cienc Saude Colet. 2012; 17(10):2665-74.

26. Santos P. Sofrimento no trabalho e imaginário organizacional: ideação suicida de trabalhadora bancária. Psicol Soc. 2011; 23(2):359-68.

27. Ceccon RF, Meneghel SN, Tavares JP, Lautert L. Suicídio e trabalho em metrópoles brasileiras: um estudo ecológico. Cienc Saude Colet. 2014; 19(7):2225-34.

28. Csillag C. Brazil's soaring suicide rate revealed. Lancet. 1996; 348(9042):1651.

29. Meneghel SN, Victora CG, Faria NMX, Carvalho LA, Falk JW. Características epidemiológicas do suicídio no Rio Grande do Sul. Rev Saude Publica. 2004; 38(6):804-10.

30. Faria NMX, Victora CG, Meneghel SN, Carvalho LA, Falk JW. Suicide rates in the State of Rio Grande do Sul, Brazil: association with socioeconomic, cultural, and agricultural factors. Cad Saude Publica. 2006; 22(12):2611-21.

31. Fialho RR. Os sentidos produzidos pelos agricultores e agricultoras familiares da cultura do fumo em relação ao trabalho [dissertação]. Santa Cruz do Sul: UNISC; 2003.

32. Becker H. Métodos de pesquisa em ciências sociais. Rio de Janeiro: HUCITEC; 1993.

33. Yin RK. Estudo de caso: planejamento e métodos. 4a ed. Porto Alegre: Bookman; 2010. 
34. Instituto Brasileiro de Geografia e Estatística. Cidades. Rio Grande do Sul [Internet]. Santa Cruz do Sul; 2016 [citado 20 Abr 2017]. Disponível em: http://cidades.ibge.gov.br/ xtras/perfil.php?codmun $=431680$

35. Gergen KJ. The social constructionist movement in modern psychology. Am Psychol. 1985; 40(3):266-75.

36. Seyferth G. Identidade étnica, assimilação e cidadania. A imigração alemã e o Estado brasileiro. In: Anais do $17^{\circ}$ Encontro Anual da ANPOCS; Caxambu; 1993.

37. Seyferth G. Imigrantes colonos: ocupação territorial e formação camponesa no Sul do Brasil. In: Neves DP, organizadora. Processos de constituição e reprodução do campesinato no Brasil. São Paulo: Ed. UNESP; 2009. v. 2, p. 39-64.

38. Weber M. A ética protestante e o espírito do capitalismo. São Paulo: Pioneira Thomson Learning; 2001.

39. Nardi HC. Saúde do trabalhador, subjetividade e interdisciplinaridade. In: Merlo AC, organizador. Saúde e trabalho no RS: realidade, pesquisa e intervenção. Porto Alegre: Ed. UFRGS; 2004. p.43-64.

40. Meneghel SN, Gutierrez DMD, Silva RM, Grubits S, Hesler LZ, Ceccon RF. Suicídio em idosos uma perspectiva de gênero. Cienc Saude Colet. 2012; 17(8):1983-92.

41. Kause S. Migrantes do tempo. Vida econômica, política e religiosa de uma comunidade de imigrantes alemães na República Velha. Santa Cruz do Sul: EDUNISC; 2002.

42. Costa CG. Migração alemã e fumicultura: a colônia de Santa Cruz (RS) no período imperial brasileiro. Rev Eletr Hist [Internet]. 2016 [citado 30 Abr 2016]; 1-19. Disponível em: http://www.unisc.br/site/spartacus/edicoes/012007/costa_carlos_gabriel.pdf.

43. Silveira RLL. Cidade, corporação e periferia urbana: acumulação de capital e segregação espacial na (re)produção do espaço urbano. Santa Cruz do Sul: EDUNISC; 2003.

44. Vogt OP. A produção de fumo em Santa Cruz do Sul, RS: (1849-1993). Santa Cruz do Sul: EDUNISC; 1997.

45. Silveira RLL. A produção da periferia urbana em Santa da Cruz do Sul-RS: o lugar dos safristas na terra do fumo [dissertação]. Florianópolis: Universidade Federal de Santa Catarina; 1997.

46. Gonçalves LRC. Determinantes espaciais e socioeconômicos do suicídio no Brasil: uma abordagem regional. Nova Econ. 2011; 21(2):281-316.

47. Fraga WS, Massuquetti A, Godoy MR. Determinantes socioeconômicos do suicídio no Brasil e no Rio Grande do Sul. In: Anais do $19^{\circ}$ Encontro de Economia da Região Sul; 2016; Florianópolis. Florianópolis; 2016 [citado 20 Abr 2017]. Disponível em: https://www. anpec.org.br/sul/2016/submissao/files_l/i3-1e941ade6f1aa8ea2da3a6a517b515df.pdf.

48. Ferreira MAF. Os produtores de fumo da bacia do Rio Pardinho: o cotidiano subalterno e a difícil mudança. In: Etges $V E$, Ferreira $M A F$, organizadores. A produção de tabaco: impacto no ecossistema e na saúde humana na região de Santa Cruz do Sul/RS. Santa Cruz do Sul: EDUNISC; 2006. p. 142-69.

49. Santos JC, Ristow MR. Uma micro história do suicídio no limite de fronteiras. In: Anais do XXVI Simpósio Nacional de História ANPUH; 2011; São Paulo. São Paulo; 2011.

50. Moura R. Narrativas sobre suicídio, cultura e trabalho em um município de colonização alemã [tese]. Porto Alegre: Universidade Federal do Rio Grande do Sul; 2016.

51. Fossati DM, Freitas CA. O caráter familiar da atividade fumageira em Santa Cruz do Sul/RS. In: Anais do $42^{\circ}$ Congresso Brasileiro de Economia e Sociologia Rural; Cuiabá; 2004. Cuiabá; 2004 [citado 20 Abr 2017]. Disponível em: http://www.sober.org.br/ palestra/12/090418.pdf 
52. Silva AR. O significado do trabalho na terra do fumo: perspectivas dos agricultores frente ao sistema integrado de produção industrial em Santa Cruz do Sul/RS [dissertação]. Santa Cruz do Sul: UNISC; 2007.

53. Dejours C. A loucura do trabalho: estudo de psicopatologia do trabalho. São Paulo: Cortez; 1992.

54. Cavalcante FG, Minayo MCS. Autópsias psicológicas e psicossociais de idosos que morreram por suicídio no Brasil. Cienc Saude Colet. 2012; 17(8):1943-54.

55. Meneghel SN, Ceccon RF, Hesler LZ. O suicídio na rota dos galpões de fumo. In: Comunicação Oral do $10^{\circ}$ Congresso Rede Unida; Rio de Janeiro; 2012. Rio de Janeiro; 2012.

56. Elias D. Globalização e fragmentação do espaço agrícola do Brasil. Rev Electr Geogr Cienc Soc. 2006; 10(218):3.

57. Santos JC, Ristow MR. Suicídios: fato social e desenvolvimentismo na base dos atentados contra a vida. Emancipação. 2010; 10(2):563-76.

58. Santos JC, Ristow MR. Excrescências do trabalho rural: o suicídio entre trabalhadores do campo. In: Anais do $4^{\circ}$ Simpósio Lutas Sociais na América Latina: Imperialismo, nacionalismo e militarismo no Século XXI; Londrina; 2010. Londrina: UEL; 2010.

Meneghel SN, Moura R. Suicidio, cultura y trabajo en un municipio de colonización alemana en el sur del Brasil. Interface (Botucatu). 2018; 22(67):1135-46.

El suicidio es un problema de salud pública de magnitud elevada y ascendiente. En Brasil, el Estado de Rio Grande do Sul ha presentado históricamente grandes tasas de mortalidad, principalmente en regiones colonizadas por alemanes. Este es un estudio de caso social, cuyas informaciones se produjeron con base en narrativas de 14 informantes clave, pertenecientes a los campos de: salud, agricultura, justicia, seguridad pública, comunicación social y educación. Los factores determinantes atribuidos por los informantes al suicidio incluyeron: la cultura germánica, la ética protestante y el sufrimiento en el trabajo que afecta a los agricultores que trabajan con el tabaco en régimen de pequeña propiedad familiar. Las reflexiones de los entrevistados señalan el suicidio como un recurso utilizado en la cultura de esos descendientes de alemanes para enfrentar las dificultades, cuya frecuencia se mantuvo con la introducción del capitalismo en el campo y con la subordinación de los agricultores a la industria del tabaco.

Palabras clave: Suicidio. Trabajo. Ética protestante. Cultura alemana. 